Canu, W. H. \& Carlson, C. L. (2003). Differences in heterosocial behavior and outcomes of ADHD-symptomatic subtypes in a college sample. Journal of Attention Disorders, 6(3): 123-133 (April 2003). Published by SAGE (ISSN: 1557-1246).

\title{
Differences in heterosocial behavior and outcomes of ADHD- symptomatic subtypes in a college sample
}

Will H. Canu and Caryn L. Carlson

\begin{abstract}
The purpose of this study was to explore heterosocial relational outcomes in a college-aged sample showing symptoms of Attention-Deficit/Hyperactivity Disorder (ADHD). Using questionnaires and a behavioral observation task, dating, sexual, and social outcomes were examined in three groups: 24 non-ADHD controls, 27 ADHD-Combined (ADHD/C) Type, and 13 ADHD-Primarily Inattentive (ADHD/IA) Type.

The ADHD/IA group showed a consistent pattern of passivity and inexperience and was perceived relatively negatively by female confederates, whereas the ADHD/C group reported increased sexual drive and early dating experience. The effects of externalizing comorbidity differed by DSM-IV ADHD subtype.

These findings indicate that ADHD-symptomatic adults differ by DSM-IV subtype in the manifestation of heterosocial deficits. Results suggest specific and divergent types of psychosocial intervention with $\mathrm{ADHD} / \mathrm{C}$ versus $\mathrm{ADHD} / \mathrm{IA}$ clients.
\end{abstract}


According to the DSM-IV (APA, 1994), the behavioral patterns that typically accompany Attention-Deficit/ Hyperactivity Disorder (ADHD) potentiate negative outcomes across several domains, including social functioning (Hinshaw \& Melnick, 1995). Little is known, however, about adulthood social outcomes for those with ADHD, and very few studies have examined heterosocial relationships as they relate to ADHD; this study examines this salient aspect of young adulthood.

\section{Peer relations in children with ADHD: Manifestation and etiology}

Peer relations problems represent one problematic area of social functioning for children with ADHD (Erhardt \& Hinshaw, 1994) with at least $50 \%$ encountering significant difficulties (Gaub \& Carlson, 1997; Guevremont \& Dumas, 1994). The peer rejection experienced by these children with $\mathrm{ADHD}$ is apparently global and immediate (Landau \& Moore, 1991). Hinshaw and colleagues found that children with ADHD were rejected by non-diagnosed controls and their ADHD group peers very quickly, being "desired as friend" less after just one day (Erhardt \& Hinshaw, 1994; Hinshaw \& Melnick, 1995).

Further research by Gaub and Carlson (1997) suggests that peer-relations impairment, characterizes ADHD across the subtypes. In their ethnically diverse sample of school children, $82 \%$ of those in the ADHD Combined type $(\mathrm{ADHD} / \mathrm{C})$ group experienced moderate or greater social impairment, as compared to $59 \%$ of the Primarily Inattentive type (ADHD/IA). These results are consistent with research by Sandler and colleagues (1993), who found that both cognitive inattention and hyperactivity independently predicted teacher-reported peer problems. Maedgen and Carlson (2000) found that parents and teachers rate children with $\mathrm{ADHD} / \mathrm{C}$ as displaying more aggressive behaviors in social interactions, whereas those with ADHD/IA were nominated as displaying more passive behaviors, suggesting potentially divergent contributions to the peer relations deficits of these two ADHD subtypes. The reactions of peers to children with primarily Inattentive versus Combined Type ADHD also tend to differ; whereas children with $\mathrm{ADHD} / \mathrm{C}$ are more likely to experience active rejection of others due to perceived inappropriateness, those with ADHD/IA - who tend to withdraw from social contact-will more often simply be ignored (Henker \& Whalen, 1999).

\section{ADHD in late adolescents and adults: Evidence of persistent psychopathology}

A substantial percentage of children diagnosed with ADHD will continue to experience clinically meaningful symptoms through young adulthood (Pelham, Vodde-Hamilton, Murphy, Greenstein, \& Vallano, 1991; Wender, 1995), 
although there is a wide range of prevalence estimates across studies (Wilens, Biederman, \& Spencer, 2002). While much of the current information on adult manifestations is anecdotal (Barkley, Murphy, \&Kwasnick, 1996b; Wender, 1995), a growing empirical literature has documented maladjustment across several domains, including neurological (e.g., Dinn, Robbins, \& Harris, 2001), educational (e.g., Mannuzza, Klein, Bessler, Malloy, \& LaPadula, 1993), and occupational (e.g., motor vehicle operation; Barkley, Murphy, \& Kwasnick, 1996a) impairments, among others (see review in Mannuzza \& Klein, 1999).

Despite the recent focus on long-term outcomes of individuals with ADHD, empirical studies of adult outcomes of children with ADHD have often omitted peer relations measures. A notable exception is the prospective study conducted by Weiss, Hechtman, Milroy and Perlman (1985). At young adult (mean age $=19.5$ ) or adult (mean age $=25$ ) intervals, their ADHD sample had fewer friends, response deficits for heterosocial-, assertion-, and jobdemand scenarios, complained of sexual problems, and reported lower general socialization, though there were no differences between ADHD and non-ADHD groups with respect to age at first intercourse or virginity status (Hechtman, Weiss, \& Perlman, 1980; Weiss, Hechtman, Perlman, Hopkins, \& Wener, 1979; Weiss, Hechtman, Milroy, \&Perlman, 1985; Weiss \& Hechtman, 1993). Similarly, Murphy and Barkley (1996) found that, relative to controls, clinically-referred adults with ADHD endorsed more interpersonal difficulties, problems with making friends, and a decreased tendency to listen to others.

\section{Dating and sex: Interactions and predictors}

Findings from Thornton's (1990) work suggest that variables such as age of first date and first steady dating positively predict onset and frequency of intercourse at age 18. Interestingly, Feldman, Rosenthal, Brown and Canning (1995) found that both peer acceptance and peer rejection in $6^{\text {th }}$ grade boys were indirectly, positively related to number of sex partners in $10^{\text {th }}$ grade through different mediating variables (accepted $6^{\text {th }}$ graders via dating and alcohol use; rejected via low self-restraint and high misconduct). Peer group composition could also interact with $\mathrm{ADHD}$ symptomatogy: if impulsive girls are attracted to boys with like characteristics, the combination may enhance early dating and sexual opportunities.

\section{Overview and Hypotheses}

While, collectively, the literature suggests that many child ADHD probands continue to display social deficits, few studies have addressed how adults with ADHD experience peer rejection. Additionally, adult ADHD has largely been treated as a unified syndrome, obscuring possible subtype differences in long-term social outcomes. This study focused on developmentally relevant areas of late adolescent and adult peer relations: dating and sexual experience and global heterosocial skills.

Three general hypotheses, derived from the combined body of ADHD and heterosocial relations literature, were specifically examined. Adults with ADHD were expected to have significantly less dating experience than non-ADHD controls. This result was expected given the likelihood of early peer rejection, a subsequent late start to dating and courtship, and inherent cognitive and behavioral deficits (notably impulsivity and inattention) that would likely contribute to early termination of relationships by dating partners. Further, adults with $\mathrm{ADHD} / \mathrm{C}$ were not expected to differ significantly from nondiagnosed control participants on amount of sexual experience. This hypothesis is supported most directly by the work done by Feldman and colleagues (1995) and Weiss and colleagues (1979), noted above. Further, the seemingly logical link between impulsivity and promiscuity, as well as the likelihood that many adolescents with ADHD will be exposed to a deviant peer group, could facilitate early sexual experience. Finally, adults with $\mathrm{ADHD} / \mathrm{C}$ and $\mathrm{ADHD} / \mathrm{IA}$ were expected to differ on heterosocial deficits, with the IA group showing more passivity and the $\mathrm{C}$ group displaying more impulsive, inappropriate responses in heterosocial situations. This hypothesis is suggested by the findings of Carlson and colleagues (Maedgen \& Carlson, 2000; Gaub \& Carlson, 1997) regarding ADHD subtype differences in childhood.

\section{Method}

\section{Participants}

Participants included in study analyses were 64,17 to 22 year old, heterosexual, undergraduate males attending a large public university in the southwest United States. The vast majority were volunteers from introductory psychology courses whose participation counted towards a research requirement. Potential participants were initially identified using the Wender Utah Rating Scale (WURS; Ward, Wender, \& Reimherr, 1993), completed again on a 
voluntary basis as part of a qualification battery for several university research studies. Recruitment was facilitated through posted sign ups and/or direct phone (or e-mail) follow-up. Three of the 64 volunteered through the university's Office of Services for Students with Disabilities and were paid $\$ 15$ for completing study procedures. Report of a prior diagnosis of ADHD was not an entry criterion. An additional 50 participants completed study procedures but were excluded from data analysis for meeting exclusion criteria such as negligible adulthood ADHD symptoms, unclear (i.e., conflicting) ADHD symptom self-reports, and/ or nonheterosexual orientation. Table 1 presents additional sample description.

\section{Diagnostic Measures}

Wender Utah Rating Scale (WURS; Ward et al., 1993). The WURS is a retrospective self-report of childhood ADHD symptoms. The abbreviated version consists of 25 items with a sensitivity of $86 \%$ and a specificity of $99 \%$ for identifying individuals with a history of ADHD. The splithalf reliability is $r=.9$; Pearson correlation coefficients with Parent Rating Scale (Conners, 1973) scores were .49 for nondiagnosed controls and .41 for adults with ADHD.

The recommend ADHD-identification cutoff score of 46 was adopted. A conservative score of 20 was chosen as an upper WURS bound for the non-ADHD control group. A post-hoc analysis of a contemporary University of Texas at Austin sample-at-large (1,341 male introductory psychology students) yielded a mean score $(M=20.9, S D=15.5)$ corresponding very closely to the initial cutoff. No control participants scored above 21 , and two outliers below the $5^{\text {th }}$ percentile (WURS $=0$, 1 , respectively) were excluded.

Conners Adult ADHD Rating Scale-Self Report: Long Version (Conners, 1997). This 66-item self-report questionnaire assesses adult ADHD manifestations. Two factor scores were used: DSM-IV Inattentive Symptoms (IA) and DSMIV Hyperactive-Impulsive Symptoms (HI). One-month testretest reliabilities for IA and $\mathrm{HI}$ are .81 and .64 , respectively. The Inattentive and Hyperactive-Impulsive scales have high positive correlations with matching DSM-IV symptom clusters (.89 and .74 , respectively) in males.

\section{Dependent Measures}

Heterosocial Initiation Task (HIT). In this naturalistic observation, modeled after the Small-Talk Initiation Task (Twentyman, Boland, \& McFall, 1981), each participant is escorted to a private "waiting room," where a female undergraduate research assistant (blind to participant's group membership) is introduced as another participant. Both are told the experimenter must leave briefly, and that afterwards the pair will separately complete their questionnaires. The confederate remains silent until the experimenter returns one minute later or until spoken to by the participant. Confederates are trained to converse neutrally. The minute-long period is recorded (by a camera in plain view), and afterwards both participant and confederate complete 5-point Likert scale ratings of

Table 1. Demographic and Symptom Characteristics

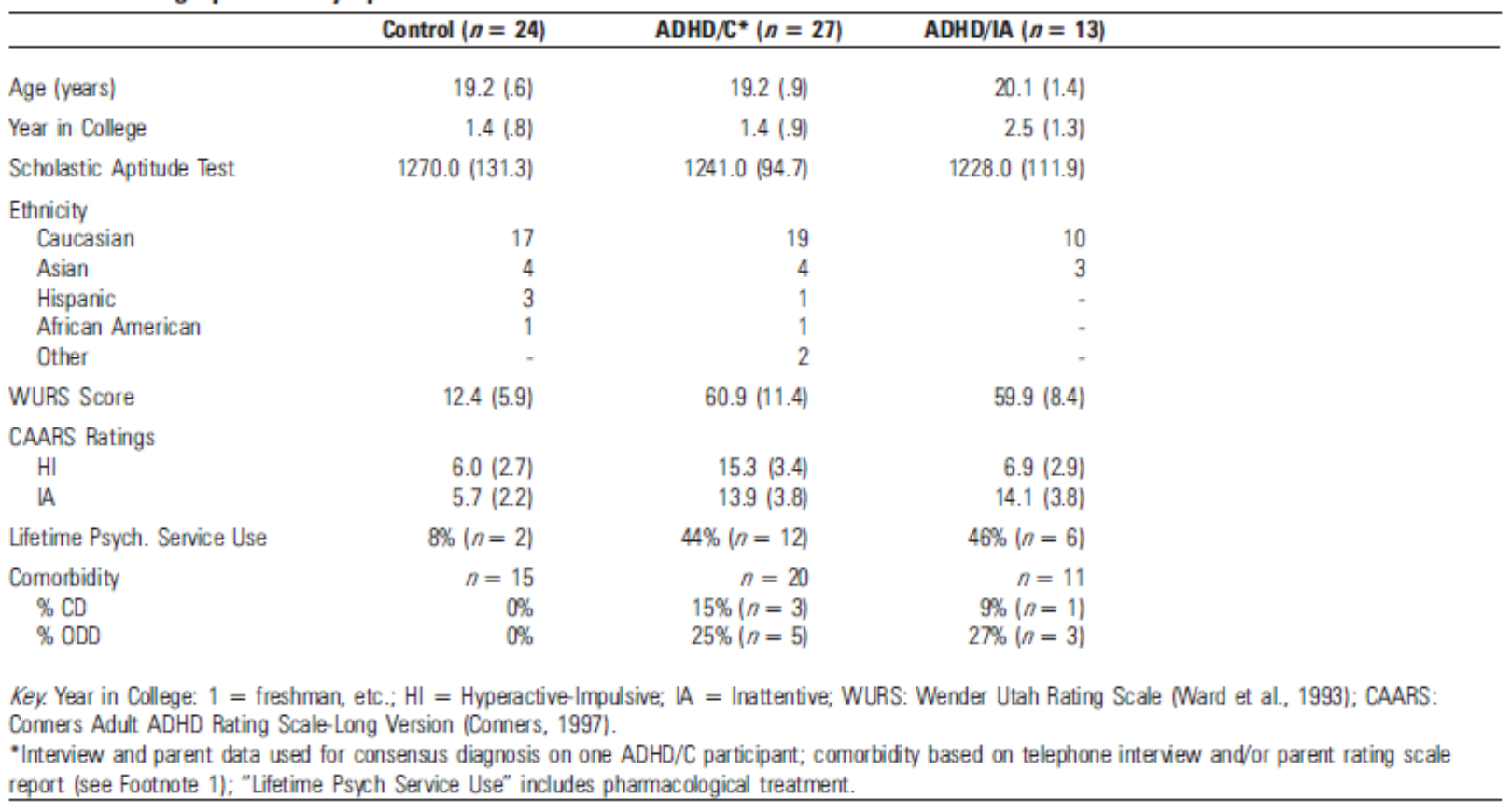


participant assertiveness, appropriateness in, and own desire to continue the interaction. Confederates also rate likelihood to consider the participant for friendship and dating. Each HIT was later rated by two other female assistants on the above dimensions as well as participant's verbosity, number of conversation initiations, comfort, and interest in the confederate.

Biographical Data Questionnaire. This 8-item measure captures variables including age, ethnicity, any lifetime psychiatric diagnoses and/or psychotherapeutic treatment, highest education level, and highest combined Scholastic Aptitude Test (SAT; 1994) score.

Dating Questionnaire. This 19-item measure assesses dating preferences and history. Two items assess current preference for short-term versus long-term dating partners (Buss \& Schmidt, 1993); four items adapted from Thornton (1990) assess timing of dating milestones (e.g., age at first date) as well as frequency of current dating. Responses are on a 7-point Likert scale. Ten similarly formatted questions were added to further assess dating (e.g., number of lifetime steady dating relationships) and related sexual escalation patterns. The remaining three items assess current dating satisfaction (on a 7-point scale), dating status (in relationship vs. not), and other factors in the participants' dating pattern (open-ended).

A principal components analysis with varimax rotation using data from all heterosexual participants $(n=105)$ yielded six factors, conceptualized as: Relationship Experience, Dating Milestones, Sexual Escalation in Dating, Short-term Dating Orientation, Dissatisfaction with Seeking Short-term Partners, and Overall Dating Drive (listed in decreasing eigenvalue). ${ }^{2}$

Sexual Experience Questionnaire. This questionnaire consists of 36-items, composed principally of the Derogatis Sexual Functioning Inventory (DSFI; Derogatis \& Melisaratos, 1979), Experience and Drive scales, and the Sociosexual Orientation Inventory (SOI; Simpson \& Gangestad, 1991). The Experience scale (24-item; internal consistency $r=.97$, test-retest $r=92$ ) uses a true-false format to assess breadth of sexual activity. The Drive scale ( 5 -item; internal consistency $r=.6$, test-retest $r=.77$ ) taps frequency (during the last year) of five sexually oriented behaviors using a 9 -point scale $(1=$ not at all, $9=4>$ times/day). Responses are coded as zero to eight points before calculating the scale score. The SOI (5-item; alpha $=.73$ ) gathers data regarding number of partners, frequency, and context of intercourse; the sum of responses yields a sociosexual restrictiveness score (higher $=$ less restrictive). The SOI correlates modestly ( $r=.27$ for men) with behaviors that suggest unrestricted sexual behavior (e.g., extra-relationship sex) in large samples of undergraduate students. A question assessing participant sexual orientation is also included.

Social Response Questionnaire (SRO). This 19-item questionnaire is largely based on the Dating and Assertion Questionnaire (Levenson \& Gottman, 1978). Two 9-item scales assess dating and assertion skills, and one additional item taps comfort level in terminating dating relationships. Questions follow a vignette format and are scored on a 4or 5-point Likert scale. Cronbach alphas for the Dating and Assertion scales are .92 and .85 , respectively, and 6-week test-retest reliability was .62 and .70 , respectively. Clients in therapy for dating or assertion deficits differed from controls on both scales.

\section{Procedures}

Data were collected from 1999 to 2001 . Rating scale information obtained from prescreening and study procedures differentiated three comparison groups: an ADHD/C symptomatic group $(n=27$; WURS $>46$; CAARS $\mathrm{HI}$ and IA scores 1 standard deviation above the mean or higher); an ADHD/IA symptomatic group ( $n=13$; WURS $>46$; CAARS IA score 1 standard deviation above the mean or higher; CAARS HI score less than 1 standard deviation above the mean), and a non-ADHD control group $(n=24$; WURS $<23$ and $>2$; CAARS HI and IA scores less than 1 standard deviation above the mean $)^{3}$. Participants were not made aware of group assignment at any time.

After a description of the study procedures was given, written informed consent was obtained. The HIT ensued, after which each participant completed a sequentially uniform battery of the questionnaires, in private. Afterwards, participants were debriefed and offered the choice of withdrawing their video-recorded HIT data after learning the true nature of the task (i.e., some deception occurred). Only two participants (3\%), both from the ADHD/ IA group, chose to withdraw their HIT data.

\section{Analytic Strategy}

Analysis of variance (ANOVA) procedures were used to evaluate nondichotomous dependent variables. For this exploratory study, we used a very liberal statistical followup rule: one-way ANOVA comparisons on items that reached $p<.25$ were further analyzed using pairwise comparisons (two-tailed $t$-tests) between groups. The potential contribution of Oppositional Defiant Disorder (ODD) and Conduct Disorder (CD) comorbidity was evaluated using $2 \times 2$ ANOVAs. Chi-square analyses were 
conducted as needed to evaluate group differences on dichotomous variables. Effect size (Cohen's $d$ ) was calculated for selected variables to illuminate the pattern of results.

\section{Results}

\section{Demographic and Descriptive Information}

Although no group differences for Scholastic Aptitude Test scores emerged, the groups differed on age $(F=3.33, d f=2,60, p=.04)$ and year in college $(F=6.49$, $d f=2,60, p=.00$ ), with the ADHD/IA group significantly higher than $\mathrm{ADHD} / \mathrm{C}$ and controls. Accordingly, when correlated substantially $(p<.10)$ with a dependent variable, these variables were covaried in subsequent ANOVA analyses.

The scores on CAARS HI and IA symptom scales for the ADHD groups were as expected; mean $T$-scores (and $S D s$ ) for the $\mathrm{ADHD} / \mathrm{C}$ group were 69.4 (8.4) and 71.3 (9.4), respectively; and those for the $\mathrm{ADHD} / \mathrm{IA}$ group were 48 (6.5) and 69.5 (8.5), respectively. Rates of ODD and CD comorbidity status and lifetime use of psychiatric services suggest that symptom expression has possibly been problematic for many.

\section{Dating and Sexual History Data}

Comparisons on dating and sexual history variables (see Table 2) suggest that, relative to those with $\mathrm{ADHD} / \mathrm{IA}$, the $\mathrm{ADHD} / \mathrm{C}$ group achieved Dating Milestones earlier (a difference that approached a large effect size). Group means on the dating initiation item of this scale were particularly telling; the ADHD/IA group had a mean age at first date of 16.2 years $(S D=1.6)$ whereas the $\mathrm{ADHD} / \mathrm{C}$ group reported reaching this milestone at 14.6 years $(S D=1.5)$, a large effect size difference (control group $M=15.4, S D=1.5$ ).
Further, the $\mathrm{ADHD} / \mathrm{C}$ group also reported higher sexual (DSFI) drive than controls; this difference also approached a large effect size. The full pattern of significant and nonsignificant findings for dating and sexual history variables is illustrated in Table 2.

While not a focus of statistical group analysis, items on the DSFI Experience scale allow a calculation of virginity (i.e., no experience with vaginal sexual intercourse) rates in the sample. The virginity rates for comparison groups were, $\mathrm{ADHD} / \mathrm{C}=44 \%(n=12)$, $\mathrm{ADHD} / \mathrm{IA}=54 \%(n=7)$, control $=62 \%(n=15)$. Similarly, an item on the Overall Dating Drive scale captures number of lifetime steady dating relationships. The mean number of these reported by group was, $\mathrm{ADHD} / \mathrm{C}=2.5(S D=1.7), \mathrm{ADHD} / \mathrm{IA}=1(S D=1.2)$, control $=2.4(S D=1.6)$. These differences between the $\mathrm{ADHD} / \mathrm{IA}$ and both other groups are large in effect size.

\section{Social Interaction and Self-Perception Data: SRO and HIT}

Analyses of SRQ and HIT variables indicate potential deficits in this domain for the ADHD/IA group. Regarding self- and confederate-reported data (see Table 3), SRQ scores indicated significantly higher comfort and ability to handle general social situations requiring self-assertion for the controls versus the ADHD/IA group, a difference that was large in effect size. Further, the ADHD/IA group indicated significantly less desire to continue with the HIT interaction than controls (nearly large effect size), and similarly talked significantly less during the HIT (medium effect size). In addition, relative to the ADHD/IA group, confederates reported significantly more willingness to consider both the control (large effect size) and $\mathrm{ADHD} / \mathrm{C}$ (medium effect size) participants as potential dating

Table 2. Dating and Sexual History Data

\begin{tabular}{|c|c|c|c|c|c|c|c|}
\hline \multirow{2}{*}{$\begin{array}{l}\text { Variable } \\
\text { Dating Questionnaire }\end{array}$} & \multicolumn{2}{|c|}{$\begin{array}{c}\text { Control } \\
(n=24)\end{array}$} & \multicolumn{2}{|c|}{$\begin{array}{r}\text { ADHD } / C \\
(n=27)\end{array}$} & \multicolumn{2}{|c|}{$\begin{array}{l}\text { ADHD/AA } \\
(n=13)\end{array}$} & \multirow[t]{2}{*}{ Differences } \\
\hline & & & & & & & \\
\hline Relationship Experience & 3.5 & $(2.8)$ & 3.6 & (3.8) & 3.0 & (3.1) & $F=.21, \rho=.81$ \\
\hline Dating Milestones ${ }^{(a+a)}$ & 12.6 & $(5.0)$ & 13.2 & (4.1) & 9.7 & (5.2) & $F=2.72, \rho=.07 \mathrm{C}>\mathrm{IA}^{*}$ \\
\hline Sexual Escalation in Dating ${ }^{3}$ & 7.6 & $(6.7)$ & 8.9 & (6.3) & 7.6 & (5.7) & $F=1.10, \rho=34$ \\
\hline S-T Dating Orientation & 5.3 & (4.5) & 5.6 & (5.6) & 4.6 & $(5.0)$ & $F=1.03, \rho=36$ \\
\hline Dissatisfaction with Seeking S-T Partners & 11.3 & (4.1) & 12.1 & (4.0) & 11.6 & (5.1) & $F=.23, \rho=.79$ \\
\hline Overall Dating Drive & 8.1 & $(2.9)$ & 8.2 & (3.7) & 6.2 & (2.9) & $F=1.89, \rho=.16$ \\
\hline \multicolumn{8}{|l|}{ Sexual Experience Questionnaire } \\
\hline DSFI Experience ${ }^{a}$ & 12.2 & $(7.7)$ & 15.0 & $(7.4)$ & 13.9 & $(7.6)$ & $F=1.22, \rho=.30$ \\
\hline DSFI Drive & 17.3 & $(7.5)$ & 23.9 & (10.1) & 19.2 & (7.7) & $F=3.76, \rho=.03 \mathrm{C}>\mathrm{N}^{*}$ \\
\hline Sexual Restrictiveness ${ }^{\circ}$ & 13.5 & $(15.3)$ & 14.2 & (13.7) & 14.3 & (18.3) & $F=.12, p=.88$ \\
\hline
\end{tabular}


partners, and reported more desire to continue the HIT with $\mathrm{ADHD} / \mathrm{C}$ participants.

Data from the second-raters' "observer's" perspective further differentiated the ADHD groups. The ADHD/C participants initiated conversation significantly more than those with $\mathrm{ADHD} / \mathrm{IA}$. Further, the $\mathrm{ADHD} / \mathrm{C}$ group was rated as more attractively assertive as compared to their ADHD/ IA peers. Results for all SRQ and HIT variables are summarized in Table 3.

In order to test the possibility that the confederate and second-rater evaluations were skewed (i.e., via a halo effect) by initial physical impressions of the participants, a group of 10 , heterosexual, undergraduate women were recruited to evaluate the participants' attractiveness. A single still image of each participant with available video footage (control $n=23, \mathrm{ADHD} / \mathrm{C} n=27, \mathrm{ADHD} / \mathrm{IA} n=10$ ) was presented to each woman using a PowerPoint presentation with instructions to rate each man's attractiveness on a 10 -point scale $(1=$ very unattractive, 10 $=$ very attractive). These women were previously unaffiliated with the investigation, were blind to participant status, and were paid $\$ 10$ for completing this task. The group means for perceived attractiveness were as follows: control $M=4.4$ (1.3), ADHD/C $M=4.0$ (1.1), ADHD/IA $M=4.5$ (.8); this equated to no statistical difference between groups $(F=.847, d f=2,57, p=.43)$, strongly suggesting that physical attractiveness did not drive differences observed on the confederate and second-rater evaluations.

\section{Comorbidity Effects}

Intragroup (comorbid vs. noncomorbid) comparisons were conducted separately for each ADHD group to determine if overall group differences could be attributed to the presence of ODD or CD. Due to small group sizes (see Table 1), ODD- and CD-comorbid cases were pooled. All dependent variables were examined; significant or trendlevel $(p<.10)$ differences for at least one of the two ADHD groups existed on eight variables: relationship experience, dating milestones, sexual escalation in dating, overall dating drive, DSFI Experience and Drive, self-rated HIT assertion, and confederate desire to continue the HIT. Two by two (Comorbidity Status x ADHD subtype) ANOVA procedures were used to analyze possible comorbidity effects. There were no main effects for comorbidity status on any of the eight variables, and main effects for ADHD subtype

Table 3. Social Interaction and Self-Perception Data: SRO and HIT

\begin{tabular}{|c|c|c|c|c|c|c|c|}
\hline \multirow{2}{*}{$\begin{array}{l}\text { Variable } \\
\text { SRQ Dating }\end{array}$} & \multicolumn{2}{|c|}{$\begin{array}{c}\text { Control } \\
(n=24)\end{array}$} & \multicolumn{2}{|c|}{$\begin{array}{l}\text { ADHD/C } \\
(n=27)\end{array}$} & \multicolumn{2}{|c|}{$\begin{array}{l}\text { ADHD/LA } \\
(n=13)\end{array}$} & \multirow[t]{2}{*}{ Differences } \\
\hline & 29.3 & $(6.4)$ & 26.9 & $(6.7)$ & 26.2 & $(5.9)$ & \\
\hline SRQ Assertion & 32.2 & $(4.0)$ & 29.3 & (6.7) & 27.9 & $(4.0)$ & $F=3.24, \rho=.05 \mathrm{~N}>1 \mathrm{~A}^{*}$ \\
\hline SRO Comfort in Ending Datinga+o & 3.2 & $(1.0)$ & 2.7 & (1.1) & 2.5 & $(.7)$ & $F=1.57, p=.22$ \\
\hline \multicolumn{8}{|l|}{ Heterosocial Interaction Task } \\
\hline \multicolumn{5}{|l|}{ Self-ratings } & \multicolumn{2}{|c|}{$(n=12)$} & \\
\hline HIT-Assertion & 2.4 & (.9) & 2.7 & $(1.1)$ & 2.2 & (.9) & $F=1.08, \rho=.35$ \\
\hline HIT-Appropriate & 3.8 & $(1.0)$ & 3.6 & (.9) & .6 & $(1.2)$ & $F=.27, \rho=.77$ \\
\hline Desire to continue $\mathrm{HIT}^{\mathrm{T}}$ & 3.2 & (.9) & 3.1 & (.8) & 2.5 & $(1.0)$ & $F=2.80, \rho=.07 \mathrm{~N}>\mathrm{IA}^{\circ}$ \\
\hline \multicolumn{8}{|l|}{ Confederate Ratings } \\
\hline HIT-Assertion & 2.2 & $(.8)$ & 2.4 & $(.8)$ & 1.9 & $(.7)$ & $F=1.73, \rho=.19$ \\
\hline HIT-Appropriate & 3.8 & (.9) & 3.9 & (.9) & 3.3 & (1.1) & $F=1.72, \rho=.19$ \\
\hline Desire to continue HIT & 2.8 & (1.1) & 2.9 & (1.1) & 2.2 & (.9) & $F=1.64, \rho=.21 \mathrm{C}>\mathrm{IA}^{*}$ \\
\hline Consider Friendship? & 3.0 & $(1.0)$ & 3.0 & (.9) & 2.5 & (.9) & $F=1.42, \rho=.25$ \\
\hline Consider Dating? & 2.5 & (.9) & 2.3 & $(.8)$ & 1.7 & (.8) & $F=3.48, \rho=.04 \mathrm{IA}<\mathrm{N}, \mathrm{C}^{*}$ \\
\hline \multicolumn{5}{|l|}{ Second Rater Data } & \multicolumn{2}{|c|}{$(n=10)$} & \\
\hline Verbosity & 29.9 & $(25.3)$ & 40.9 & $(30.0)$ & 16.9 & $(12.8)$ & $F=1.55, \rho=23 \mathrm{C}>\mathrm{IA}^{\circ}$ \\
\hline Conversational Initiations & 2.7 & $(2.2)$ & 3.3 & $(2.0)$ & 2.0 & $(2.0)$ & $F=1.66, \rho=.20 \mathrm{C}>\mathrm{IA}^{*}$ \\
\hline HIT-Assertion & 2.2 & $(.8)$ & 2.5 & $(.6)$ & 2.0 & $(.6)$ & $F=2.69, \rho=.08 \mathrm{C}>\mathrm{IA}^{\circ}$ \\
\hline HIT-Appropriate & 3.6 & $(.7)$ & 3.7 & (.8) & 3.5 & $(.4)$ & $F=.50, \rho=.61$ \\
\hline HIT-Comfort & 2.9 & (.9) & 2.7 & $(.8)$ & 2.4 & (.8) & $F=1.00, \rho=.38$ \\
\hline HIT-Interest & 2.7 & (1.2) & 3.1 & (1.1) & 2.4 & (.9) & $F=1.50, \rho=.23$ \\
\hline Desire to continue HIT & 1.9 & $(1.0)$ & 1.9 & $(.8)$ & 1.5 & (.5) & $F=1.24, \rho=.30$ \\
\hline Consider Friendship? & 2.3 & $(.8)$ & 2.3 & (.7) & 2.1 & (.6) & $F=.33, p=.72$ \\
\hline Consider Dating? & 1.9 & $(.7)$ & 1.8 & (.5) & 1.6 & $(.5)$ & $F=.71, \rho=.49$ \\
\hline \multicolumn{8}{|c|}{$\begin{array}{l}\text { Key. HIT = Heterosocial Interaction Task; SRQ }=\text { Social Response Questionnaire; } N=\text { Non-ADHD Control; } C=A D H D / C ; I A=A D H D / I A \\
=\text { significant difference upon pairwise group comparison }(p<.05) ;{ }^{\prime}=\text { irverse scores reported for ease of interpretation; }{ }^{a+a}=\text { Age and Year in college } \\
\text { were covaried. } \\
\text { Note. Three IA participants excluded }(n=2) \text { or had no videotaped HIT data (see reduced } / \mathrm{s}) \text {. }\end{array}$} \\
\hline
\end{tabular}


matched results from initial analyses. Interestingly, there was an interaction for Sexual Escalation in Dating $(F=4.37, d f=1,36, p=.04)$ and Confederate Desire to Continue HIT $(F=4.01, d f=1,35, p=.05$; see Figure 1). Further, nearly significant interactions were observed for the DSFI Sexual Experience $(F=3.79, d f=1,36$, $p=.06)$ and Drive $(F=3.32, d f=1,36, p=.08)$ scales. For all of these variables, differences between noncomorbid subgroups were insubstantial, whereas comorbid ADHD/IA participants showed more dysfunction than their comorbid $\mathrm{ADHD} / \mathrm{C}$ peers.

\section{Effect-Size Comparisons}

Table 4 is included to consolidate and detail effect size data for the between group comparisons, discussed above.

\section{Discussion}

Results suggest the existence of salient differences between the ADHD subtypes, with the ADHD/IA group likely experiencing some heterosocial impairment. This group reached dating milestones at a later age than those with $\mathrm{ADHD} / \mathrm{C}$ (e.g., mean age at first date: $\mathrm{ADHD} / \mathrm{C}$ $M=14.6$, ADHD/IA $M=16.2$; controls $M=15.4$ ). In addition, there was a large effect size difference between the $\mathrm{ADHD} / \mathrm{IA}$ and both other groups on the individual item of number of steady dating relationships. The $\mathrm{ADHD} / \mathrm{IA}$ group also reported being less comfortable and assertive in relevant situations (versus controls), and were rated most negatively by the HIT confederates and observers alike. The latter result is striking, given that the HIT is a one-minute interaction, which suggests that young men with ADHD/IA symptoms may be more likely to experience rapid negative evaluation by female peers. However, the limited duration and context (i.e., waiting in a room for an experiment) of the HIT mandate caution in interpreting findings. Finally, the ADHD/IA group's low verbosity and self-reports of low desire to continue the interaction further suggest discomfort in this situation, so typical of heterosocial interactions.

The ADHD/C group, in contrast, did not exhibit clear heterosocial deficits, showing no relative deficits on the HIT, initiating dating at an age similar to controls, and scoring comparably on the SRQ scales. In fact, both confederates and observers rated the $\mathrm{ADHD} / \mathrm{C}$ group as most attractively assertive in the HIT, although this was only significant in the case of the observer ratings and in comparison to the $\mathrm{ADHD}$ / IA group. The ADHD/C participants reported a higher sexual drive versus controls, which could have contributed to their "normalized" overall dating motivation level and composite sexual experience (both comparable to controls). However, selection criteria may have resulted in the control group in this sample being less sexually experienced or adventurous than the typical college population (see Limitations).

\section{Clinical Implications}

While the current study is primarily exploratory, some possible treatment implications emerge. Findings indicate that

Figure 1. Comorbidity x ADHD Subtype Interactions

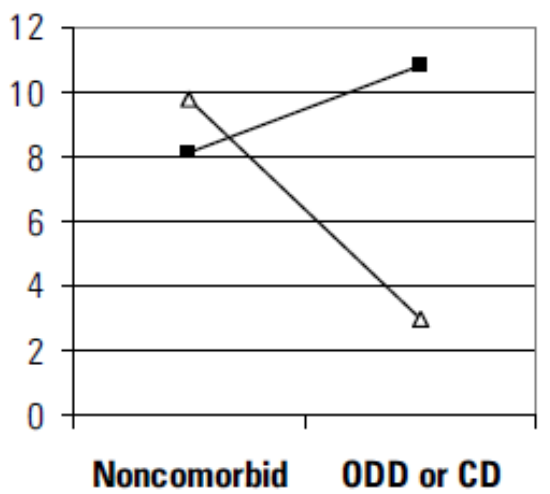

$$
\begin{aligned}
& \longrightarrow-\mathrm{ADHD} / \mathrm{C} \text { (n) } 27 ; \text { comorbid }=8 \text { ) } \\
& \longrightarrow \triangle \mathrm{ADHD} / \mathrm{A} \text { (n }=13 ; \text { comorbid }=4 \text { ) }
\end{aligned}
$$

Sexual Escalation in Dating ${ }^{a}$

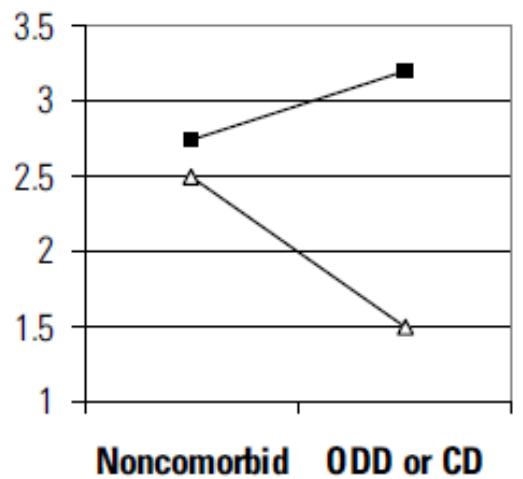

$\rightarrow-\mathrm{ADHD} / \mathrm{C}(\mathrm{n}=27 ;$ comorbid $=8)$
$\rightarrow-\mathrm{ADHD} / \mathrm{AA}(\mathrm{n}=12 ;$ comorbid $=4)$

Confederate Desire to Continue HIT'

Key. *higher score $=$ faster initiation of sex (possible range $=3-21$ ): ${ }^{b} 1=$ not at all, $5=$ very much (score and scale are inverted for ease of interpretation); HIT = Heterosocial Interaction Task. 
Table 4. Selected Effect Sizes

\begin{tabular}{|c|c|c|c|}
\hline Variable & Control vs. ADHD/C & Control vs. ADHD//A & ADHD/C vs. ADHD/LA \\
\hline Dating Milestones & -.13 & .57 & .79 \\
\hline Age at First Date* & -.55 & .56 & 1.12 \\
\hline \# Steady Dating Relationships". & -.08 & .95 & .96 \\
\hline DSFI Drive Scale & -.73 & -.26 & .49 \\
\hline SRQ Assertion & .51 & 1.08 & .25 \\
\hline Self-rated Desire to continue HIT & .18 & .77 & .67 \\
\hline HIT Verbosity & -.39 & .59 & .90 \\
\hline Consider for dating? (HIT confederate) & .23 & .89 & .73 \\
\hline \multicolumn{4}{|c|}{$\begin{array}{l}\text { Key. DSA = Derogatis Sexual Functioning Inventory (Derogatis \& Melisaratos, 1979); HI = Heterosocial Interaction Task; SRO = Social Response } \\
\text { Questionnaire. } \\
\text { "Age at First Date loads on Dating Milestones; “" Steady Dating Relationships is an item from the Overall Dating Drive scale, for which there were no } \\
\text { significant overall differences. } \\
\text { Note. Effect size }>.20=\text { small, }>.50=\text { medium, }>.80 \text { large (Cohen, 1992). Negative effect sizes indicate lower values in the first group listed; positive } \\
\text { values indicate higher values in the first group listed. Effect sizes are Cohen's } d \text {. }\end{array}$} \\
\hline
\end{tabular}

adolescent males with $\mathrm{ADHD} / \mathrm{IA}$ may be most at risk for opposite-sex peer rejection, given this group's delayed dating, low HIT verbosity, and the quickly realized negative evaluation by female conversation partners and observers in our brief behavioral observation task. Perhaps, in early adolescence, impulsive behaviors associated with ADHD/ $\mathrm{C}$ become attractive to girls - a kind of class-clown or badboy magnetism. Those with ADHD/IA, lacking impulsivity, would still be rejected, exacerbating low self-esteem and shyness, and stalling heterosocial development. Accordingly, special attention could be given to education and building skills relevant to successful heterosocial relationship initiation.

Although the $\mathrm{ADHD} / \mathrm{C}$ group displayed no global pattern of heterosocial impairment, the combination of early dating experience and higher sexual drive with inherent impulsivity warrants clinical sensitivity to safe-sex adherence.

\section{Limitations}

While the effect size analyses suggest that demonstrated group differences are robust, there are several study limitations. The foremost weaknesses are the small sample and liberal analytic strategy. This is particularly true for the $\mathrm{ADHD} / \mathrm{IA}$ group, which is only approximately half the size of the other two comparison groups. The possible subclinical status of the ADHD groups also presents a challenge in interpreting the results; while a more clinically symptomatic group might have even more distinct differences, it is also possible that the current sample differs from more clinically severe ones. In addition, this sample is probably atypical of the overall ADHD population, so generalization should be made cautiously.

Another limitation to study design is that group assignment (i.e., identification as ADHD-symptomatic) was based exclusively on self-report questionnaire items. While recent research (Murphy \& Schachar, 2000) has documented that adult self-report of ADHD symptoms, collected via a questionnaire, correlate highly with like parent and significant-other reports, it is still recommended that multiple sources of information be used for clinical diagnosis (Barkley, Fischer, Smallish, \& Fletcher, 2002).

It is also possible that controls in this study are actually sexually under-experienced. The control group had a $62 \%$ virginity rate, which is higher than $37 \%$ and $30 \%$ virginity rates in comparable, normative samples (Meston, Trapnell, \& Gorzalka, 1996; Thornton, 1990). The screening criteria resulted in the selection of control participants with, on average, a WURS score about one-half a standard deviation below our population's mean. This procedure, designed to increase the efficiency of non-ADHD control identification, may have biased that group toward sexual inhibition.

\section{Future Directions}

One factor that could have limited our interpretations but now seems a direction for future research is externalizing comorbidity. Our data suggest that such comorbidity in $\mathrm{ADHD} / \mathrm{C}$ and $\mathrm{ADHD} / \mathrm{IA}$ groups is socially manifested or interpreted differently. ODD/CD comorbidity here appears to paradoxically enhance heterosocial "success" for the $\mathrm{ADHD} / \mathrm{C}$ group, whereas outcomes for comorbid ADHD/ IA participants were less positive than those of both their noncomorbid peers and the $\mathrm{ADHD} / \mathrm{C}$ comorbid group. Further investigation could unravel this phenomenon. Other possible directions include examining the partner characteristics of individuals with ADHD, safe-sex compliance and perceptions, and collecting samples of actual dating behavior. Finally, the limited sample and liberal statistical strategy used here underscore the preliminary nature of this evidence for differing adult heterosocial 
outcomes across ADHD subtypes; we believe, however, these findings help establish a base for future research to expand upon using larger samples and more conservative analyses.

\section{Acknowledgments}

This study was partially funded through a Sigma-Xi Grantin-Aid-of-Research to the first author. Selected results were presented at the American Psychological Association meeting in Washington, D.C. (2000) and the International Society for Research on Child and Adolescent Psychopathology in Vancouver, B.C., Canada (2001). We would like to express our sincere gratitude to Kelsey McKay, Narissa Oomer, Bonnie Coover, Duncan Bywater, Jacob Harris, and Daughon Langner for their valuable assistance over the course of this investigation.

\section{Notes}

${ }^{1}$ Information from two additional assessment instruments was collected for a subsample of study participants. A follow-up structured telephone interview for ADHD and disruptive behavioral disorders-modeled after Carlson, Swanson, and Taylor's (1994; unpublished)—was conducted by the first author with $48 \%(n=19)$ of participants with ADHD. Further mention of this measure is excluded as this other self-report differed insubstantially from CAARS reports of ADHD symptomatology. Barkley and Murphy's Childhood Symptom Scale-Other Report Form (CSS; Barkley \& Murphy, 1998) was collected from a parent of $73 \%(n=47)$ of participants. CSS data supported group assignment-with significant differences on Hyperactive-Impulsive $(F=5.14, d f=2,44, p=.01)$ and Inattentive $(F=11.21, d f=2,44, p=.00)$ symptom scalesyet suggested that some ADHD participants have exhibited only subclinical-level impairment. Since this college sample should probably be considered high functioning and because retrospective parent reports could thusly be skewed, the CSS was not used for group assignment. Note that data concerning $\mathrm{ODD} / \mathrm{CD}$ comorbidity that was collected with these instruments has been included (see Table 1); criteria for designation as ODD or CD follow DSM-IV.

${ }^{2}$ Dating Questionnaire factors are composed as follows.

- Factor 1 (Relationship Experience): Raw number of past dating relationships of 1 to 3 months, 3 to 6 months, 6 to 12 months, and 1 year or longer; range $=0$ tol 4 .

- Factor 2 (Dating Milestones): Age at first date, regular (at least once every 2 months) dating, and steady dating with one partner; range $=3$ (achieved all milestones before age 14) to 21 (achieved all milestones after age $18 /$ not at all).

- Factor 3 (Sexual Escalation in Dating): Least number of dates with someone before having (oral, vaginal, or anal) sex, most number of times for same, average number of times for same; range $=3$ (more than 11 dates before sex or abstinence on all 3 items) to 21 ( 0 -1 dates before sex on all 3 items)

- Factor 4 (Short-term Dating Orientation): Number of different dating partners in last 4 weeks and past dating relationships of less than 1 month; range $=0$ to 21 .

- Factor 5 (Dissatisfaction with Seeking Short-term Partners): Satisfaction with current dating pattern (reversed), degree to which participant is seeking a longterm romantic partner (reversed), degree to which a shortterm partner is sought; range $=3$ (satisfaction and shortterm partner orientation) to 21 (dissatisfaction and longterm partner orientation).

- Factor 6 (Overall Dating Drive): Number of dates and number of partners dating initiation was attempted with in past 4 weeks, number of lifetime steady dating relationships; range $=3$ (no attempts, dates, or steady relationships) to 21 (attempted w/6+ partners, 11+ dates, 6+ steady relationships).

Questionnaire form and factor loading matrix available upon request.

${ }^{3}$ Due to the general nature of cutoff scores, it is possible that those assigned to the ADHD/IA group (1 standard deviation above the mean or higher on CAARS F Scale) would differ little from those in the ADHD/C group (1 standard deviation above the mean or higher on CAARS F Scale) on Hyperactive-Impulsive symptoms. In this study, none of the members of the ADHD/IA group had a justbelow-cutoff score on the CAARS F Scale, creating a natural separation between the two groups.

\section{References}

American Psychiatric Association (APA). (1994). Diagnostic and Statistical Manual of Mental Disorders $\left(4^{\text {th }}\right.$ ed.). Washington, DC: Author.

Barkley, R.A., Fischer, M., Smallish, L., \& Fletcher, K. (2002). The persistence of attention-deficit/hyperactivity disorder into young adulthood as a function of reporting source and definition of disorder. Journal of Abnormal Psychology, 111(2), 279-289. 
Barkley, R. A., Murphy, K., \& Kwasnik, D. (1996a). Motor vehicle driving competencies and risks in teens and young adults with attention deficit hyperactivity disorder. Pediatrics, 98(6 pt 1), 1089-1095.

Barkley, R. A., Murphy, K., \& Kwasnik, D. (1996b). Psychological adjustment and adaptive impairments in young adults with ADHD. Journal of Attention Disorders, 1(1), 41-54.

Barkley, R. A., \& Murphy, K. R. (1998). Attention deficit hyperactivity disorder: A clinical workbook ( $2^{\text {nd }} \mathrm{ed}$.). New York: Guilford.

Buss, D. M., \& Schmitt, D. P. (1993). Sexual strategies theory: An evolutionary perspective on human mating. Psychological Review, 100(2), 204-232.

Carlson, C. L., Swanson, J. M., \& Taylor (1994). Carlson Swanson - Taylor Interview for DSM ADHD/ODD/ CD Diagnoses. Department of Psychology, University of Texas at Austin.

Cohen, J. (1992). A power primer. Psychological Bulletin, 112(9), 155-159.

Conners, C. K. (1973). Rating scales for use in drug studies with children. Psychopharmacology Bulletin, 9, $24-85$.

Conners, C. K. (1997). Conners Rating Scales: Revised Technical Manual. Toronto, Canada: Multi-Health Systems.

Derogatis, L. R., \& Melisaratos, N. (1979). The DSFI: A multidimensional measure of sexual functioning. Journal of Sex \& Marital Therapy, 5(3), 244-281.

Dinn, W. M., Robbins, N. C., \& Harris, C. L. (2001). Adult attention-deficit/hyperactivity disorder: Neuropsychological correlates and clinical presentation. Brain \& Cognition, 46(1-2), 114-121.

Erhardt, D., \& Hinshaw, S. P. (1994). Initial sociometric impressions of attention-deficit hyperactivity disorder and comparison boys: Predictions from social behaviors and from nonbehavioral variables. Journal of Consulting and Clinical Psychology, 62(4), 833-842.
Feldman, S. S., Rosenthal, D. R., Brown, N. L., \& Canning, R. D. (1995). Predicting sexual experience in adolescent boys from peer rejection and acceptance during childhood. Journal of Research on Adolescence, 5(5), $387-411$.

Gaub, M., \& Carlson, C. L. (1997). Behavioral characteristics of DSM-IV ADHD subtypes in a school-based population. Journal of Abnormal Child Psychology, 25(2), 103-111.

Guevremont, D. C., \& Dumas, M. C. (1994). Peer relationship problems and disruptive behavior disorders. Journal of Emotional and Behavioral Disorders, 2(3), $164-172$.

Hechtman, L., Weiss, G., \& Perlman, T. (1980). Hyperactives as young adults: Self-esteem and social skills. Canadian Journal of Psychiatry, 25(6), 478-483.

Henker, B., \& Whalen, C. K. (1999). The child with attentiondeficit/hyperactivity disorder in school and peer settings. In R. J. Sternberg, and M. Hojjat (Eds.), Satisfaction in close relationships (pp. 56-77). New York: Guilford.

Hinshaw, S. P., \& Melnick, S. M.(1995). Peer relationships in boys with attention-deficit hyperactivity disorder with and without comorbid aggression. Development and Psychopathology, 7(4), 627-647.

Landau, S., \& Moore, L. A. (1991). Social skill deficits in children with attention-deficit hyperactivity disorder. School Psychology Review, 20(2), 235-251.

Levenson, R. W., \& Gottman, J. M. (1978). Toward the assessment of social competence. Journal of Consulting and Clinical Psychology, 46(3), 453-462.

Mannuzza, S., \& Klein, R. G. (1999). Adolescent and adult outcomes in attention-deficit/hyperactivity disorder. In H. C. Quay, and A. E. Hogan (Eds.), Handbook of disruptive behavior disorders (pp. 279-294). New York: KluwerAcademic/Plenum. 
Mannuzza, S., Klein, R. G., Bessler, A., Malloy, P., \& LaPadula, M. (1993). Adult outcome of hyperactive boys: Educational achievement, occupational rank, and psychiatric status. Archives of General Psychiatry, 50(7), 565-576.

Maedgen, J. W., \& Carlson, C. L. (2000). Social functioning and emotional regulation in the attention deficit hyperactivity disorder subtypes. Journal of Clinical Child Psychology, 29(1), 30-42.

Meston, C. M., Trapnell, P. D., \& Gorzalka, B. B. (1996). Ethnic and gender differences in sexuality: Variations in sexual behavior between Asian and non-Asian university students. Archives of Sexual Behavior, 25(1),33-71.

Murphy, K., \& Barkley, R. A. (1996). Attention deficit hyperactivity disorder adults: Comorbidities and adaptive impairments. Comprehensive Psychiatry, 37(6), 393-401.

Murphy, P., \& Schachar, R. (2000). Use of self-ratings in the assessment of symptoms of attention deficit hyperactivity disorder in adults. American Journal of Psychiatry, 157(7), 1156-1159.

Pelham, W. E., Vodde-Hamilton, M., Murphy, D. A., Greenstein, J., \& Vallano, G. (1991). The effects of methylphenidate on ADHD Adolescents in recreational, peer group, and classroom settings. Journal of Clinical Child Psychology, 20(3), 293-300.

Sandler, A. D., Hooper, S. R., Watson, T. E., Coleman, W. L., Footo, M., \& Levine, M. D. (1993). Talkative children: Verbal fluency as a marker for problematic peer relationships in clinic-referred children with attention deficits. Perceptual and Motor Skills, 76(3 pt 1), 943-951.

Schol astic Aptitude Test (1994). Princeton, NJ: Educational Testing Service.

Simpson, J. A., \& Gangestad, S. W. (1991). Individual differences in sociosexuality: Evidence for convergent and discriminant validity. Journal of Personality and Social Psychology, 60(6), 870-883.
Thornton, A. (1990). The courtship process and adolescent sexuality. Journal of Family Issues, 11(3), 239-273.

Twentyman, C. T., Boland, T., \& McFall, R. M. (1981). Heterosocial avoidance in college males: Four studies. Behavior Modification, 5(5), 523-552.

Ward, M. F., Wender, P. H., \& Reimherr, F. W. (1993). The Wender Utah Rating Scale: An aid in the retrospective diagnosis of childhood attention deficit hyperactivity disorder. American Journal of Psychiatry, 150(6), 885-890.

Weiss, G., Hechtman, L., Perlman, T., Hopkins, J., \& Wener, A. (1979). Hyperactives as young adults: A controlled prospective ten-year follow up of 75 children. Archives of General Psychiatry, 36(6), 675-681.

Weiss, G, Hechtman, L., Milroy, T., \& Perlman, T. (1985). Psychiatric status of hyperactives as adults: A controlled prospective 15-year follow-up of 63 hyperactive children. Journal of the American Academy of Child Psychiatry, 24(2), 211-220.

Weiss, G., \& Hechtman, L. T. (1993). Hyperactive children grown up: $A D H D$ in children, adolescents, and adults ( $2^{\text {nd }}$ ed.). NewYork: Guilford.

Wender, P. H. (1995). Attention-deficit hyperactivity disorder in adults. New York: Oxford University Press.

Wilens, T. E., Biederman, J., \& Spencer, T. J. (2002). Attention-deficit/hyperactivity disorder across the lifespan. Annual Medical Review, 53, 113-131.

Will H. Canu is a doctoral candidate with the Department of Psychology at the University of Texas at Austin. Caryn L. Carlson is Professor and Co-director of clinical training in the Department of Psychology at the University of Texas at Austin.

Correspondence concerning this article should be sent to Caryn L. Carlson, Department of Psychology, The University of Texas at Austin, 1 University Station, \#A8000, Austin, Texas, 78712-0187. 